\title{
Potential of community based approach for prevention of anaemia among women of childbearing age from rural India
}

\author{
Shobha Rao \\ Biometry \& Nutrition Group, Agharkar Research Institute, Pune 411 004, India \\ Email address: \\ raoari@yahoo.com
}

\section{To cite this article:}

Shobha Rao. Potential of Community Based Approach for Prevention of Anaemia among Women of Childbearing Age from Rural India. Journal of Food and Nutrition Sciences. Vol. 2, No. 6, 2014, pp. 270-276. doi: 10.11648/j.jfns.20140206.15

\begin{abstract}
Objective: Investigate impact of community based programs for creating nutrition and health awareness of women of child bearing age for prevention of anemia. Design: Intervention comprising of informal meetings, live demonstrations of iron rich recipes from green leafy vegetables and kitchen garden activity. Women with $\mathrm{Hb}<11 \mathrm{~g} / \mathrm{dl}$ had to be given iron folic acid tablets and formed the supplemented group (SG) while those with $\mathrm{Hb}>11 \mathrm{~g} / \mathrm{dl}$ formed non supplemented group (NSG). Settings: Three villages near Pune city, Maharashtra, India. Subjects: Rural non pregnant women $(\mathrm{n}=317)$ of childbearing age (15-35 yr). Results: Prevalence of severe anemia $(\mathrm{Hb}<10 \mathrm{~g} / \mathrm{dl})$ reduced significantly from $19.2 \%$ to $7.1 \%$ and $11.0 \%$ in the first and second year respectively. At the end of first year, the proportion of women shifting into higher grade of $\mathrm{Hb}$ was significantly lower in NSG (38.2\%) compared to SG (71.6\%), but was exclusively due to interventions. Further, proportion of women showing such improvement in $\mathrm{Hb}$ was significantly $(\mathrm{p}=0.003)$ higher $(61.5 \%)$ among women with higher participation ( $>=50 \%$ meetings) compared to those with $(29.8 \%)$ lower participation ( $<25 \%$ meetings). This was also true with regard to actual practice of repeating the demonstrated iron rich recipes at home. Impact after two years was reduced, however, the participation in interventional activities continued to show association with improvement in $\mathrm{Hb}(\mathrm{p}=0.06)$. Conclusion: Our observations highlight that developing action programs for improving nutritional awareness to enhance consumption of iron rich foods through dietary diversification has great potential for preventing anaemia in rural India.
\end{abstract}

Keywords: Anemia, Community Based Intervention, Rural Indian Mothers

\section{Introduction}

Iron deficiency anaemia resulting from inadequate intake and low absorption of dietary iron is the most common form of anaemia in India ${ }^{(1,2)}$. The National Nutritional Anaemia Control Program distributes iron folic acid tablets to pregnant women and the existing program has been repeatedly shown to be ineffective in reducing the prevalence of anaemia ${ }^{(3,4,5)}$ and reasons mentioned are poor access to prenatal care, insufficient and inconsistent supply of iron supplements, insufficient counseling on the need for and the benefits of iron supplements and more importantly an unwillingness by pregnant women to take iron supplements ${ }^{(6)}$. Consequently, in India, dose has been increased from $60 \mathrm{mg}$ of elemental iron to $100 \mathrm{mg}$ but it is unlikely to bring beneficial effects for reducing anaemia as iron deficiency is likely to be compounded by multiple micronutrient deficiencies. An alternative to supplementation approach is therefore to increase consumption of micronutrient rich foods.
Reported data shows that maternal intakes of rural Indian mothers are not only low in energy and $\operatorname{protein}^{(7-10)}$ but the consumption of foods that are important sources of micronutrients such as green leafy vegetables (GLVs), fruits, milk, meat etc. is extremely low in rural Indian population ${ }^{(5)}$. It follows that, in addition to supplementation programs of iron/folic acid tablets, simultaneous efforts for increasing consumption of micronutrient rich vegetarian foods are also essential. GLVs form the food group of potential interest as they are rich and cheapest source of all vitamins and minerals and are easily available compared to fruits and milk. Increasing the intake of GLVs would however, call for several actions such as improving their availability, dietary diversification by incorporating GLVs in the diet and ways to improve the iron bioavailability from them as in many populations, especially with limited access to hem-iron rich animal foods, poor bioavailability of iron is also a major 
contributor.

Clearly community based actions are required to achieve these goals. For example, women can be instrumental in attempting dietary diversification by preparing iron rich recipes using locally available ingredients and therefore would need nutritional knowledge and awareness about iron rich foods. Secondly, active self help groups (SHG) of rural women can be involved with kitchen garden activities to increase the availability of GLVs throughout the year. But such actions have not been evaluated for their possible impact on prevention of anemia. More research is urgently needed to evaluate the potential of dietary approaches in combating the major health problem like anemia. There is growing realization that specific programs for addressing the nutritional and health requirements of women of child bearing age is a key strategy for reaching population health targets. Present study describes an approach for tackling anemia which is major health problem of women of child bearing age in rural India.

\section{Subjects and Methods}

Three Indian villages (Dhamari, Hivare and Pimple) which were largely homogeneous, situated within $45 \mathrm{~km}$ from Pune district, Maharashtra, were considered for the study. Census was done for all houses in these villages to get the list of eligible women and women were enrolled in the study only after their oral consent. It covered total population of 8300 individuals and the initial number of eligible (15-35 yr ages) non pregnant women was 317. Most women were from subsistence farming community with marginal land holding and were residing in an extended family with their in-laws.

\subsection{Personal Information}

Each enrolled woman in the study was interviewed by a nutritionist in a house to house visit, with field tested structured questionnaire for getting personal information, measuring anthropometric measurements and obtaining obstetric history. Personal information comprised of her current age, age at menarche, age at marriage, education, type of income generating work, if engaged in any work other than household work etc.

\subsection{Anthropometry}

Women were measured for weight (up to $200 \mathrm{gm}$ ) using portable digital display weighing balance (ATCO, India), and height was measured (up to $0.1 \mathrm{~cm}$ ) using stadiometer.

\subsection{Obstetric History}

Information on parity, outcome of previous deliveries and complications if any, place of delivery, birth weight of offspring if known, practice of giving colostrum etc. was also recorded.

\subsection{Dietary Assessment}

Food frequency questionnaire (FFQ), developed in an earlier study ${ }^{(11)}$ for rural mothers from villages in the same area, was used for assessing their habitual dietary patterns. Nevertheless, it was field tested before using in this study but no changes were required. During follow up, FFQ was repeated every six months.

\subsection{Hemoglobin (Hb) Estimation}

A trained technician accompanying a research team drew venous blood sample $(2 \mathrm{ml})$ and collected it in EDTA tubes which were transported to a pathological laboratory in Pune, taking proper precautions. The samples were immediately analyzed for $\mathrm{Hb}$ by cynemethemoglobin method and red blood cells (RBC) morphology (i.e. color, size and shape), the details of which are reported earlier ${ }^{(12)}$.

\subsection{Composition of Research Team and Their Roles}

Research team comprising of a lady doctor, two nutritionists and a technician visited once a fortnight to each of the study village. The lady doctor conducted informal meetings for imparting health related information while the nutritionist talked about the nutrition related issues. Nutritionists developed and standardized iron rich recipes from locally available GLVs and explained the importance of checking $\mathrm{Hb}$ and also provided initial and recurrent training to community health workers for keeping various types of qualitative and quantitative records related to intervention. The technician was responsible for collecting the blood samples of women.

\subsection{Community Health Worker (CHW)}

Young married girls from local community, having good rapport with rural women, acted as a mediator between the research team \& study subjects. They helped to motivate women for attending meetings and for giving blood sample, visited each women couple of times to inform about the date and time of meetings, kept the attendance record of the meetings, distributed the blood report and accompanied the technician for collecting the blood sample of women not attending the meetings.

\subsection{Developing Iron Rich GLV Recipes}

Major considerations in developing the recipes were incorporating GLVs in their staple foods like roti (sorghum bread), dal (pulse curry) etc. using locally available low cost ingredients, keeping preparations easy, palatable, less time consuming and having variety of options for substitution. Further, attention was also given to important micronutrients like folic acid, vitamin $\mathrm{C}$, beta carotene and calcium, which are known to be beneficial for fetal growth. About hundred recipes were developed from 13 commonly consumed GLVs in this community viz., amaranth, onion stalk, shepu (Peucedanum graveolens), bathua leaves (Chenopodium album), safflower leaves, radish leaves, spinach, fenugreek leaves, ambat chuka (Rumex vesicarius) etc. using singly or in combinations to maximize micronutrient content. 


\subsection{Salient Features of Standardized Recipes}

Our main concern was that the recipes developed should remain within the habitual diet pattern. Thus Wheat roti (Paratha) with addition of GLVs and spices was not very much known to rural people but was appreciated due to its taste, while spicy roti (Thalipith) incorporating GLV ensured increased intake of macro and micronutrients. Further, it saved time as there was no need to make separate vegetable/ side dish. Similarly, seasoned rice with spring onion, cabbage leaves and some spices was nutritious, tasty, most popular recipe ensuring increased intake of micronutrients. Dry besan ( preparation from Bengal gram flour) and dal preparation with addition of GLV ensured increased frequency of GLV consumption, as it is a most commonly consumed item in all rural families. Salad was never a part of rural diet but due to its easy preparation especially with addition of lemon juice increased iron bioavailability and ensured maximum benefit (nutrient security). Soup made from GLV was not only rich in vitamins but also had suitable texture for young and old ones. Chilly chutney which is part and parcel of their daily diet was enriched with micronutrients by adding GLVs and lemon juice.

\section{Interventions}

The intervention comprised of couple of community based social actions. Developing iron rich recipes from commonly consumed GLVs and organizing their live demonstrations regularly for improving nutritional knowledge and awareness was one of the major action programs.

\subsection{Informal Meetings}

During monthly meetings lady doctor discussed wide range of issues related to pregnancy, such as increased requirements in pregnancy, importance of macro \& micronutrients in relation to birth size \& anaemia, complications in pregnancy, importance of giving colostrums, appropriate breast feeding and weaning practices, symptoms and adverse effects of anaemia etc. Similarly, the nutritionist discussed the sources of micronutrients, importance of seasonal fruits like guava, tamarind, zizapus which are rich sources of Vit C, and benefits of eating raw salads etc. Several activities were associated with these informal meetings. Total of 56 such informal meetings were organized during the study period (Table 1).

Table 1. Interventional activities undertaken during study period.

\begin{tabular}{lccc}
\hline Activity & 1st Year & 2nd Year & Total \\
\hline No. of Meetings & 31 & 25 & 56 \\
Avg. no. of women present per meeting & 22 & 17 & 20 \\
Standardization of recipes done & 48 & 49 & 97 \\
Live demonstrations organised & 27 & 29 & 56 \\
\hline
\end{tabular}

A poster showing the pictures and messages related to causal factors, symptoms \& implications of anaemia was prepared for giving it to each enrolled woman.

\subsection{Live Demonstrations of Iron Rich Recipes From GLVS}

In each informal meeting, nutritionist arranged a live demonstration of 3 to 4 recipes from a particular GLV, explaining the importance of different ingredients used and describing the possible substitute for these ingredients. Recipes prepared were given along with roti for actual tasting, to women attending the meeting. The activity of live demonstrations of recipes became popular as cooking is dear to rural women and it made a significant impact. At the end of the meeting, each woman was given a bunch of the GLV so that they would repeat at least one of the recipes demonstrated, for their evening meal. The description of recipes was prepared for distribution and additional copies were kept with CHW for those who could not attend the meeting. Similarly, a poster, summarizing various recipes of GLVs with their pictures was prepared and was given to all eligible women.

\subsection{Kitchen Garden Activity}

Women who were interested in kitchen garden activity were given seedlings and its stock was kept with CHW for those not attending the meeting. They were demonstrated simple ways of kitchen gardening such as use of half folded gunny bags for planting the seeds, use of waste water from kitchen, from washing utensils, from bathing etc., simple ways of fencing for protecting the vegetables from goats \& other domestic animals. This activity was aimed to increase the availability of GLVs at their doorstep.

\subsection{Statistical Methods}

Differences and linearity in mean $\mathrm{Hb}$ values for different groups of women were tested using one way analysis of variance (ANOVA). Proportions of women with IDA in various categories of anthropometric measurements were tested for trend using chi-square test. Multiple logistic regression analysis was carried out for computing odds ratios for risk of IDA associated with various factors. All the analysis was carried out using SPSS/PC+ 11.0 version for Windows. Ethical permission was obtained from Institutional Ethical Committee before implementing the project.

\section{Results}

As per existing Government program iron tablets $(60 \mathrm{mg}$ of elemental iron) were given to women with $\mathrm{Hb}<11 \mathrm{~g} / \mathrm{dl}$. However, the analysis was done separately for supplemented and not supplemented groups for examining the impact of interventions involving social actions.

\subsection{Hb Distribution in Successive Years}

Distribution of $\mathrm{Hb}$ in successive yearly rounds for non pregnant women (Fig. 1) shows the shift of distribution to the right in the two successive years. It can be seen that (Table 2) prevalence of severe anaemia $(\mathrm{Hb}<10 \mathrm{~g} / \mathrm{dl})$ reduced significantly at the end of first and second year with 
subsequent significant increase in proportion of women with normal $\mathrm{Hb}$ levels. The overall prevalence of anaemia reduced significantly at the end of first year (from $82 \%$ to $55.4 \%$ ) but increased to $74.6 \%$ at the end of second year. However, considering iron deficiency anemia (IDA) the initial prevalence $(30.3 \%)$ reduced significantly $(10.8 \%)$ at the end of first year and remained low (14.4\%) at the end of second year.

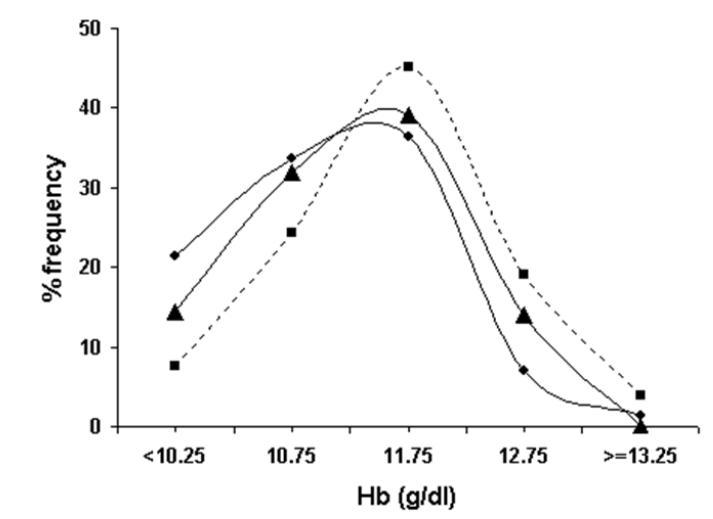

* Initial

- - After 1 yr

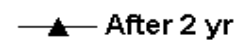

Fig 1. Hb distribution for non-pregnant women in successive years

Table 2. Distribution of Hb in successive rounds for Non-pregnant women.

\begin{tabular}{lccc}
\hline Hb $(\mathbf{g} / \mathbf{d l})$ & Initial & ${\text { After } \mathbf{1}^{\text {st }} \text { year }}$ & After $\mathbf{2}^{\text {nd }}$ year \\
\hline$<10$ & $61(19.2)$ & $17(7.1)^{* *}$ & $32(11.0)^{*}$ \\
$10-11$ & $65(20.5)$ & $31(12.9)$ & $64(22.0)$ \\
$11-12$ & $134(42.3)$ & $85(35.9)$ & $121(41.6)$ \\
$>=12$ & $57(18.0)$ & $107(44.6)^{* *}$ & $74(25.4)^{*}$ \\
$\%$ prev. anemia & $260(82.0)$ & $133(55.4)^{* *}$ & $217(74.6)$ \\
$\%$ iron def. & $96(30.3)$ & $26(10.8)^{* *}$ & $42(14.4)^{* *}$ \\
Total & 317 & 240 & 291 \\
\hline
\end{tabular}

Figures in parenthesis give percentages.

$*: \mathrm{p}<0.05 * * \mathrm{p}<0.01$ when compared with initial status.

Women were cross classified by their initial levels of $\mathrm{Hb}$ and the levels at the end of first year as shown schematically in Table 3.

Compared to initial level of $\mathrm{Hb}$, women who moved in the higher level of $\mathrm{Hb}$ can be considered as those showing 'improvement' while those shifting to a lower level of $\mathrm{Hb}$ can be considered as showing 'deterioration' of iron stores. However, those remaining in the same level of $\mathrm{Hb}$ as before would be considered as women showing 'no change' or maintaining their $\mathrm{Hb}$ status.

Table 3. Schematic representation of assessing change in Hb in follow up study

\begin{tabular}{|c|c|c|c|c|}
\hline \multirow{2}{*}{ Initial Hb (g/dl) } & \multicolumn{4}{|c|}{ Final Hb (g/dl) } \\
\hline & $<10$ & 10-11 & 11-12 & $>=12$ \\
\hline$<10$ & $\begin{array}{rllll}0 & 0 & 0 & 0 & 0 \\
0 & 0 & 0\end{array}$ & $\begin{array}{c}++++++ \\
+\end{array}$ & $\begin{array}{c}++++ \\
+++\end{array}$ & $\begin{array}{c}+++++ \\
+++\end{array}$ \\
\hline $10-11$ & - - - - - & $\begin{array}{c}0000000 \\
00\end{array}$ & $\begin{array}{c}++++ \\
+++\end{array}$ & $\begin{array}{c}+++++ \\
+++\end{array}$ \\
\hline $11-12$ & $-\ldots$ & $-\ldots$ & 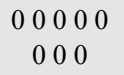 & $\begin{array}{c}++++ \\
+++\end{array}$ \\
\hline$>=12$ & - - - - - & $\begin{array}{c}-- \\
-\end{array}$ & - - - - - & $\begin{array}{rllll}0 & 0 & 0 & 0 & 0 \\
0 & 0 & 0\end{array}$ \\
\hline
\end{tabular}

+ :Cells showing 'improvement' in Hb level over a period of time

-:Cells showing 'deterioration' in Hb level over a period of time

0 : Cells showing 'no change' in $\mathrm{Hb}$ level over a period of time

The assessment of change in $\mathrm{Hb}$ after 1 year and after 2 years period of intervention is shown in Table 4 . It can be observed that among supplemented group there was a significant improvement $(71.6 \%)$ at the end of one year and only negligible proportion (2.7\%) showed deterioration. However, among non supplemented group, the improvement was seen only in $38.2 \%$ women while the deterioration in $\mathrm{Hb}$ was seen in $20 \%$ women. Thus the women in the supplemented group had definitely greater benefit due to iron tablets. Nevertheless, in the non supplemented group the improvement seen was quite sizeable and was exclusively due to dietary diversification.

Table 4. Percentage of women showing change in $\mathrm{Hb}$ at the end of first and second year of the study

\begin{tabular}{|c|c|c|c|c|}
\hline \multirow{3}{*}{ Change in $\mathbf{H b}$} & \multicolumn{2}{|l|}{ Supplemented (SG) } & \multicolumn{2}{|c|}{ Non supplemented (NSG) } \\
\hline & After $1^{\text {st }}$ yr & After $2^{\text {nd }} \mathrm{yr}$ & After $1^{\text {st }}$ yr & After $2^{\text {nd }}$ yr \\
\hline & $(n=74)$ & $(n=82)$ & $(n=110)$ & $(n=122)$ \\
\hline Improvement in $\mathrm{Hb}$ level & 71.6 & 68.3 & 38.2 & 18.5 \\
\hline No change in $\mathrm{Hb}$ level & 25.7 & 28.1 & 41.8 & 43.0 \\
\hline Deterioration in $\mathrm{Hb}$ level & 2.7 & 3.7 & 20.0 & 38.5 \\
\hline
\end{tabular}

For the entire period of two years, the women in the supplemented group continued to show similar benefits while in the non supplemented group, the proportion of women showing improvement reduced by almost half $(18.5 \%)$ and the proportion of women showing deterioration almost doubled $(38.5 \%)$ but a large proportion (43\%) maintained their $\mathrm{Hb}$ status. Although the impact of intervention with social actions was reduced in the second year, large proportion of women remained in the same category of $\mathrm{Hb}$.

\subsection{Change in Hb Levels in Relation to Intervention}

In order to see the impact of interventional activities on $\mathrm{Hb}$ status we analyzed the data for the non supplemented group. Women were classified by their participation levels (low vs. high) in these actions and their change in $\mathrm{Hb}$ after the period of one year and after 2 years was studied. It can be seen that (Fig. 2) after 1 year, proportion of women showing improvement $(61.5 \%)$ in $\mathrm{Hb}$ was significantly $(\mathrm{p}=0.003)$ higher among women with higher participation in meetings 
( $>=50 \%$ meetings) compared to the proportion $(29.8 \%)$ among lower participation ( $<25 \%$ meetings). This was also confirmed by the inverse association between participation in meetings and the proportion of women showing deterioration in $\mathrm{Hb}(3.8 \%$ vs. $29.8 \%, \mathrm{p}=0.003)$. This was also true with regard to the activity of actual practice of repeating the demonstrated iron rich recipes at home. Thus, proportion of women showing improvement $(52.9 \%)$ in $\mathrm{Hb}$ was significantly $(\mathrm{p}=0.03)$ higher among women with higher participation ( $>=50 \%$ recipes) compared to the proportion $(32.6 \%)$ among lower participation $(<25 \%$ recipes $)$. Once again, the inverse association between participation and the proportion of women showing deterioration in $\mathrm{Hb}(5.9 \%$ vs. $23.5 \%, p=0.01)$ was significant. With regard to the participation in kitchen garden activity similar trends were also seen but were not statistically significant.
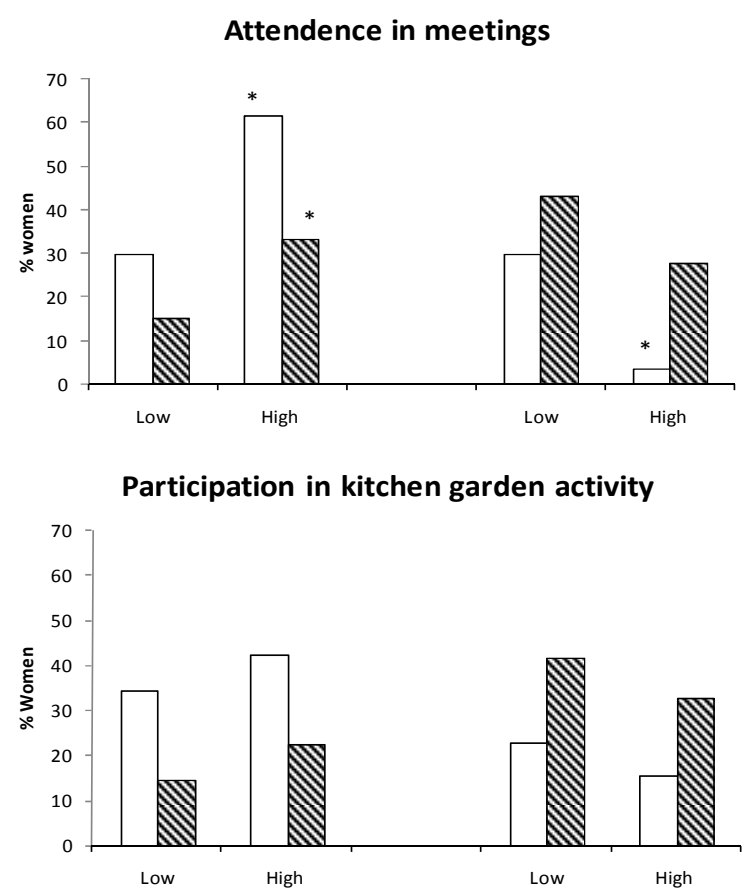

Recipes done at home

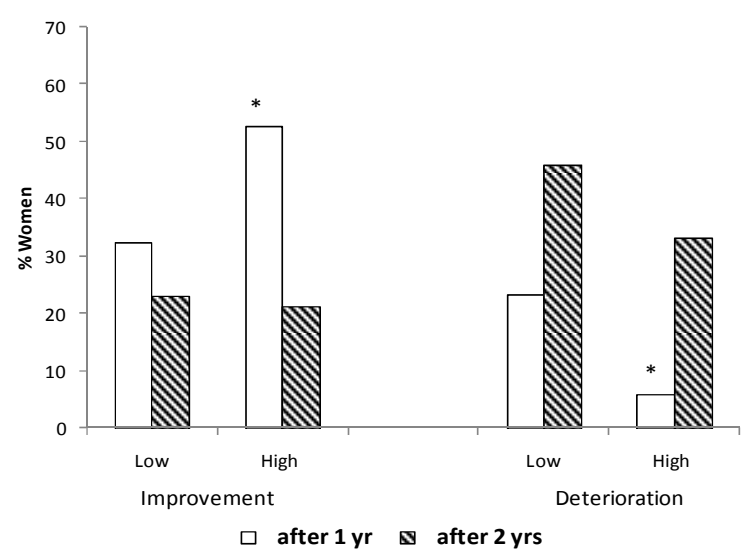

Fig. 2. Improvement / deterioration in $\mathrm{Hb}$ by levels of participation in interventional activities by women from non supplemented group (NSG)

Similar analysis for assessing impact after two years showed that the overall impact was reduced. However, the participation in meetings (low vs. high) continued to show association with improvement in $\mathrm{Hb}(\mathrm{p}=0.06)$ and inverse association with deterioration though with marginal significance $(p=0.09)$.

\subsection{Increased Consumption of GLVs During Study Period}
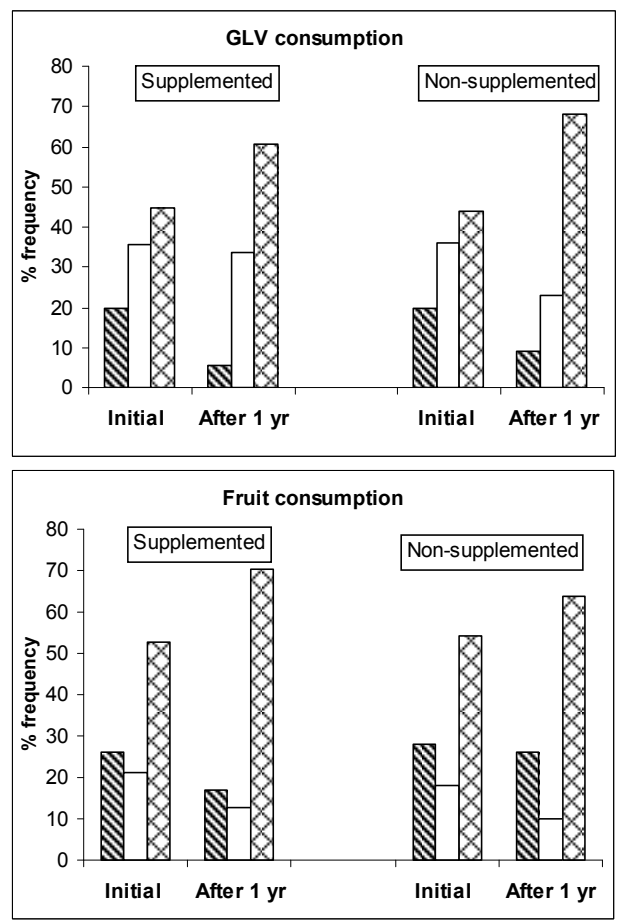

\section{$\mathrm{Q}<$ Once a week $\square<$ twice a week $\mathrm{O}>=$ twice a week}

Fig 3. Frequency of consumption for GLV and Fruit in initial year and after one year.

The impact of informal meetings for creating nutritional awareness can be seen by comparing the frequencies of consumption of GLVs which are major source for dietary iron in rural areas. It can be seen (Fig 3) that the proportion of women consuming GLVs more than twice a week has increased substantially in the first year and remained high in the second year of the study. Further, it was seen that among non-supplemented group, who improved their $\mathrm{Hb}$ during the study period, the frequency of consuming GLVs more than twice a week increased significantly from $46.2 \%$ to $72.7 \%$. There was also a significant change in the consumption of locally available seasonal fruits, especially citrus fruits, during the second year of the study, both in supplemented and non supplemented group.

\section{Discussion}

It is believed that lack of knowledge of the causes and consequences of nutritional deficiencies may influence food choices even in resource poor populations ${ }^{(13)}$. Therefore, education to change knowledge, attitudes and household dietary practices may be required to effect positive changes in consumption and nutritional status of mothers from rural 
India. Food based approaches to combat deficiencies of micronutrients deserve great attention because they are likely to be sustainable in the long term and intake of all the micronutrients will increase simultaneously.

In India, prevalence of anemia in pregnant women has been reported to be in the range of $33 \%$ to $89 \%$ in different studies $^{(3,4,14-18)}$ covering pregnant or non pregnant women of childbearing age. Our observations indicate that the prevalence of anemia among non pregnant women of child bearing age was as high as $82 \%$ and reduced to $55.4 \%$ after the administration of the interventions for one year. Based on the RBC morphology it was seen that the prevalence of iron deficiency anemia was about one third (30.3\%) and reduced significantly in the first year $(10.8 \%)$ and second year too (14.4\%). Iron deficiency anaemia resulting from inadequate intake and low absorption of dietary iron is the most common form of anaemia in India ${ }^{(1,2)}$. However, it is worthwhile to note that the National Nutritional Anaemia Control Program distributes iron folic acid tablets to pregnant women but does not cover the non pregnant women of childbearing age. Further, the evaluation of the national program conducted during 1985-86 showed no impact on the prevalence of anaemia ${ }^{(19)}$. It is for this reason our observations indicating the significant reduction in the prevalence through participatory social actions assume importance.

The impact of the intervention is often reported in terms of mean change in $\mathrm{Hb}$ over the period of intervention. In contrast, we analyzed the follow up data, to estimate the proportion of women moving to a higher or lower grade of $\mathrm{Hb}$. As expected, in supplemented group the proportion of women showing improvement was consistently higher (above $70 \%$ ) in the first year as well as in the second year. On the other hand non supplemented group showed such an improvement among 38.2\% women in the first year and $18.5 \%$ in the second year with large number of women $(43 \%)$ maintaining their $\mathrm{Hb}$ level. The public health approach of iron fortification of food have had success in the US in reducing the prevalence of anemia in women of reproductive age $^{(20)}$ but such approaches though feasible in developed countries are impractical in economically poor countries. Therefore, an alternative to supplementation is to increase the consumption of micronutrients rich foods. Our findings support this argument and highlight the need for more research to evaluate dietary approaches, especially those using vegetables, for combating iron deficiency in vegetarian populations.

The two important activities of our intervention were informal meeting in the presence of lady doctor and a nutritionist for creating nutritional and health awareness and the live demonstrations of iron rich recipes developed within their habitual diet pattern using simple locally available ingredients. The improvement in $\mathrm{Hb}$ was significantly higher $(61.5 \%$ vs. $29.8 \%)$ among women with higher participation ( $>50 \%$ meetings) than those with lower participation $(<25 \%$ meetings). It was also significantly higher among those who frequently prepared at home, the iron rich recipes shown during the demonstrations, indicating that nutritional knowledge was transformed into action. In Indonesia, social marketing played a critical role in increasing the consumption of Vit. A from plant and animal sources ${ }^{(21)}$. Moreover, single micronutrient deficiencies are rare and it is likely that iron deficiency in anemic subjects is compounded by multiple micronutrient deficiencies ${ }^{(22)}$. Our finding thus support the suggestion ${ }^{(23)}$ that a multi dietary strategy using a feasible educational program combined with identifying and promoting best choices of iron rich foods is required to increase consumption of animal source of iron and vegetables with iron absorption enhancers such as Vit. C.

Finally, the FFQ data clearly indicated that among women showing improvement in their $\mathrm{Hb}$, the frequency of consuming GLVs more than twice a week increased significantly from $46.2 \%$ to $72.7 \%$ in the non-supplemented group. It was also true with regard to consumption of locally available seasonal fruits, especially citrus fruits both in supplemented and non supplemented group. These observations in fact ensured that the change in $\mathrm{Hb}$ was actually through increase in consumption of iron rich foods achieved through the live demonstrations of iron rich recipes. These observations are in confirmation with those reported from rural central Mexico, showing that better iron status was associated with higher intakes of non heme iron and foods that contain ascorbic acid ${ }^{(24)}$. The larger the prevalence of anaemia, the more likely it is to have multiple causes and not be related solely to iron deficiency. Therefore, an alternative to iron supplementation approach is to increase consumption of micronutrient rich foods and more research is urgently needed to evaluate dietary approaches, especially those using vegetables which provide combination of micronutrients.

In practice, the efficiency of large scale programs has been limited for various reasons ${ }^{(1)}$. Besides, malarial infections and worm infestations, the known factors associated with anemia, are commonly prevalent in rural areas. Nevertheless, the importance of dietary deficiencies cannot be overlooked as iron deficiency anaemia resulting from inadequate intake and low absorption of dietary iron has been shown to be the most common cause of anaemia in $\operatorname{India}^{(1,2)}$. Our observations highlight that creating nutritional and health awareness among rural mothers have yielded sustainable results and achieving it through appropriate social actions may provide the long term success.

\section{Acknowledgement}

Sources of funding: The work was supported by the 'Science for Equity Empowerment and Development (SEED)' Division of Department of Science and Technology, New Delhi.

Conflicts of interest: The authors have no conflicts of interest.

Authors' contributions: S.R. was the Principal Investigator and was responsible for planning of the study, analysing and interpreting the results and writing the manuscript 
Acknowledgements: The authors wish to thank the funders for providing funds to carry out the research. The author would also like to acknowledge the contribution from Mrs. Smita Joshi, Mrs. Pradnya Bhide, Mrs. Bhairavi Puranik and Mrs. Asawari Kanade in the field work. Thanks are also due to all the community health workers and the rural mothers who participated in the study.

\section{References}

[1] Toteja GS \& Singh P (2004) Micronutrient Profile of Indian Population. New Delhi: Indian Council of Medical Research.

[2] Rao BSN (1978) Studies on iron deficiency anaemia. Indian J Med Res Suppl. 68, 58-69.

[3] Sood SK, Ramachandran K, Mathur M et al. (1975) WHO sponsored collaborative studies on nutritional anaemia in India. 1. The effects of supplemental oral iron administration to pregnant women. Q J Med 44, 241-258.

[4] ICMR Task Force Study (1989) Evaluation of the National Nutritional Anaemia Prophhylaxis Programme. New Delhi: Indian Council of Medical Research.

[5] Ramachandran P (1989) Nutrition in pregnancy. In Women and Nutrition in India, pp. 153-193 [C Gopalan and S Kaur, editors]. New Delhi: Nutrition Foundation of India Special Publication Services.

[6] Bothwell $\mathrm{TH}$ (2000) Iron requirements in pregnancies and strategies to meet them. Am J Clin Nutr 72, 1 Suppl., 257S264S.

[7] Vijayalaxmi P, Kuputhai U \& Meenakshi Devi N (1988) Nutritional profile of selected expectant mothers and the cost of pregnancy. Indian J Nutr Diet 25, 247-253.

[8] Ratwani L \& Varma M (1989) A study of nutritional status and food practices of the pregnant and lactating women residing in selected desert areas of Jodhpur. Indian J Nutr Diet $26,304-310$.

[9] Piers LS, Diggavi S, Thangam S et al. (1995) Changes in energy expenditure, anthropometry and energy intake during the course of pregnancy and lactation in well nourished Indian women. Am J Clin Nutr 61, 501-513.

[10] Hutter I (1996) Reduction of food intake during pregnancy in rural South India. Trop Med Int Health 1, 399-405.

[11] Shobha Rao, Chittaranjan S Yajnik, Asawari Kanade, Caroline HD Fall, Barrie M Margetts, Alan A Jackson, Rosaleen Shier, Sadhana Joshi, Sonali Rege, Himangi Lubree. Intake of micronutrient-rich foods in rural Indian mothers is associated with the and size of their babies at birth : Pune Maternal Nutrition Study ${ }^{1}$, Journal of Nutrition, 2001,131,1217-1224.
[12] Rao S, Joshi S, Bhide P, Puranik B, Kanade A. Social dimensions related to anaemia among women of childbearing age from rural India. Journal of Public Health Nutrition, 2011, 14(2), 365-72.

[13] Jones KM, Specio SE, Shrestha P et al. (2005) Nutrition knowledge and practices and consumption of vitamin A rich plants by rural Nepali participants and non participants in a kitchen garden program. Food Nutr Bull 26, 198-208.

[14] Seshadri S, Sharma K, Ra AE et al. (1994) Iron supplementation to control pregnancy anaemia. Proc Nutr Soc India 41, 131-140.

[15] ICMR Task Force Study (1992) Field Supplementation Trials in Pregnant Women with $60 \mathrm{mg}, 120 \mathrm{mg}$ and $180 \mathrm{mg}$ of Iron with $500 \mathrm{mcg}$ of Folic Acid. New Delhi: Indian Council of Medical Research.

[16] Christian P, Abbi R, Gujral S et al. (1989) At risk status of pregnant women of Panchmahals (Gujarat) and Ghandrapur (Maharashtra). Arogya J Health Sci 15, 85-91.

[17] Agarwal DK, Agarwal KN \& Tripathi AM (1987) Nutritional status in rural pregnant women of Bihar and Uttar Pradesh. Indian Pediatr 24, 119-125.

[18] Sarin AR (1995) Severe anaemia of pregnancy: recent experience. J Gynaecol Obstet 50, Suppl. 27, 545-549.

[19] ICMR Task Force Study (1989) Evaluation of the National Nutritional Anaemia Prophhylaxis Programme. New Delhi: Indian Council of Medical Research.

[20] Beard JL (2000) Effectiveness and strategies of iron supplementation during pregnancy. Am J Clin Nutr 71, 5 Suppl., 1288S-1294S.

[21] de Pee S, Bloem MW, Satoto, Satoto, Yip R, Sukaton A, Tjiong R, Shrimpton R, Muhilal, Kodyat B. Impact of a social marketing campaign promoting dark-green leafy vegetables and eggs in Central Java, Indonesia. Int J Vitam Nutr Res 1998; 68: 389-98.

[22] Ahmed F, Khan MR, Akhtaruzzaman M et al. (2005) Efficacy of twice weekly multiple micronutrient supplementation for improving the hemoglobin and micronutrient status of anemic adolescent school girls in Bangladesh. Am J Clin Nutr 82, 829-835.

[23] Amani R \& Soflaei M (2006) Nutrition education alone improves dietary practices but not hematologic indices of adolescent girls in Iran. Food Nutr Bull 27, 260-264.

[24] Backstrand JR, Allen LH, Black AK et al. (2002) Diet and iron status of non pregnant women in rural Mexico. Am J Clin Nutr 76, 156-164. 